\title{
Enteropathogenic Escherichia coli translocate Tir and form an intimin-Tir intimate attachment to red blood cell membranes
}

\author{
Robert K. Shaw, ${ }^{1}$ Sarah Daniell, ${ }^{2}$ Gad Frankel ${ }^{2}$ and Stuart Knutton ${ }^{1}$
}

Author for correspondence: Stuart Knutton. Tel: +44 121333 8746. Fax: +44 1213338701. e-mail:s.knutton@bham.ac.uk

1 Institute of Child Health, University of Birmingham, Birmingham $\mathrm{B} 46 \mathrm{NH}$, UK

2 Centre for Molecular Microbiology and Immunology, Department of Biosciences, Imperial College of Science, Technology and Medicine, London SW7 2AZ, UK

\begin{abstract}
Type III secretion allows bacteria to inject effector proteins into host cells. In enteropathogenic Escherichia coli (EPEC) the type III secreted protein, Tir, is translocated to the host-cell plasma membrane where it functions as a receptor for the bacterial adhesin intimin, leading to intimate bacterial attachment and 'attaching and effacing' (A/E) lesion formation. To study EPEC type III secretion the interaction of EPEC with monolayers of red blood cells (RBCs) has been exploited and in a recent study [Shaw, R. K., Daniell, S., Ebel, F., Frankel, G. \& Knutton, S. (2001). Cell Microbiol 3, 213-222] it was shown that EPEC induced haemolysis of RBCs and translocation of EspD, a putative poreforming type III secreted protein in the RBC membrane. Here it is demonstrated that EPEC are able to translocate and correctly insert Tir into the RBC membrane and produce an intimin-Tir intimate bacterial attachment, identical to that seen in A/E lesions. Following translocation Tir did not undergo any change in apparent molecular mass or become tyrosine-phosphorylated and there was no focusing of RBC cytoskeletal actin beneath intimately adherent bacteria, and no pedestal formation. This study, employing an RBC model of infection, has demonstrated that Tir translocation can be separated from hostcell-mediated Tir modifications; the data show that the EPEC type III protein translocation apparatus is sufficient to deliver and correctly insert Tir into host-cell membranes independent of eukaryotic cell functions.
\end{abstract}

Keywords: type III secretion, adhesion, cell-cell interactions, EPEC

\section{INTRODUCTION}

Enteropathogenic E. coli (EPEC), an established aetiological agent of human infantile diarrhoea, is a bacterial pathogen that subverts intestinal epithelial cell function to produce distinctive 'attaching \& effacing' (A/E) lesions, lesions that are characterized by localized destruction (effacement) of brush border microvilli, intimate bacterial attachment to the host-cell membrane and formation of an actin-rich cytoskeletal structure beneath intimately attached bacteria (Knutton et al., 1987). Similar lesions are also produced in a variety of cultured epithelial cell lines (Knutton et al., 1989). All the genes required for $\mathrm{A} / \mathrm{E}$ lesion formation are encoded by the LEE (locus of enterocyte effacement) pathogenicity island (McDañiel \& Kaper, 1997), which

Abbreviations: $A / E$, attaching and effacing; DAPI, diamidino-2-phenylindole; EPEC, enteropathogenic Escherichia coli; RBC, red blood cell. encodes a type III secretion system (Jarvis et al., 1995), type III secreted proteins EspA, EspB and EspD (Frankel et al., 1998), an intimate EPEC adhesin, intimin (Jerse et al., 1990), and an intimin receptor, Tir (Kenny et al., 1997), that is translocated and inserted into the host-cell membrane by the EPEC type III system where it binds to intimin. Intimin-Tir interaction leads to cytoskeletal accumulation beneath intimately attached bacteria and A/E lesion formation (Goosney et al., 2000). Two further LEE-encoded proteins, EspF (McNamara et al., 2001) and Map (Kenny \& Jepson, 2000), are translocated into the host-cell cytosol by the type III secretion system, although these EPEC effector proteins do not appear to be involved in A/E lesion formation.

Tir translocation into host cells requires a chaperone, CesT (Elliott et al., 1999), the LEE type III secretion system and type III secreted proteins EspA, EspB and EspD (Frankel et al., 1998). EspB (Wolff et al., 1998) and EspD (Wachter et al., 1999) have been shown to be 
delivered to the host-cell membrane and, based on homology with pore-forming proteins of Shigella (IpaB/IpaC) and Yersinia (YopB/YopD), are proposed to form a pore complex in the host-cell membrane (Frankel et al., 1998). EspA, on the other hand, is the major component of a large filamentous structure (Knutton et al., 1998) proposed to provide a hollow conduit for protein translocation between pores in the bacterial membrane (type III secretion system) and pores in the host cell (EspB/EspD-generated pore) (Frankel et al., 1998).

Injection of proteins into host cells by Shigella and Yersinia spp. has been correlated with their ability to cause contact-dependent haemolysis of red blood cells (RBCs) in vitro in which bacteria are brought into close contact with the RBC membrane by centrifugation (Clerc et al., 1986; Hakansson et al., 1996); EPEC were also recently shown to exhibit contact-dependent haemolytic activity (Warawa et al., 1999). However, because long EspA filaments mediate binding of EPEC to RBCs, we showed that close bacterial-RBC contact is not a requirement for EPEC-induced haemolysis (Shaw et al., 2001). Haemolysis was consistent with insertion of a hydrophilic pore into the RBC membrane and, following haemolysis, EspD was associated with the RBC membrane. However, by Western blotting we were unable to detect RBC membrane-associated Tir. As several fundamental questions regarding Tir translocation (e.g. the means by which a soluble bacterial protein becomes an integral membrane protein receptor, the mechanism by which Tir becomes focused beneath attached bacteria and the requirements for Tir modification for intimate Tir-intimin interaction) remain unanswered, we have continued to develop this model of type III protein translocation. Here we show that the EPEC type III secretion system can efficiently translocate and correctly insert native Tir into the RBC membrane where it binds intimin and forms an intimate bacterial attachment typical of that seen in $\mathrm{A} / \mathrm{E}$ lesions.

\section{METHODS}

Bacterial strains and plasmids. The EPEC strains used in this study are listed in Table 1 . Stock $-20{ }^{\circ} \mathrm{C}$ cultures of the strains were subcultured in Luria broth or Luria broth supplemented with kanamycin $\left(100 \mu \mathrm{lml}^{-1}\right)$ or ampicillin $\left(100 \mu \mathrm{l} \mathrm{ml} l^{-1}\right)$ as appropriate and incubated aerobically for $18 \mathrm{~h}$ at $37^{\circ} \mathrm{C}$. In some studies bacteria were passaged daily for 4 days in Luria broth.

Infection of RBC monolayers. Human blood was obtained from laboratory volunteers. RBCs were sedimented, washed three times in PBS and a $3 \%$ suspension added to polylysinecoated $13 \mathrm{~mm}$ glass cover slips in 24-well culture plates or $30 \mathrm{~mm}$ tissue culture dishes for $20 \mathrm{~min}$. Non-attached RBCs were removed by further washing with PBS and the resulting RBC monolayer was covered with HEPES-buffered Dulbecco's Modified Eagle's Medium (DMEM). An overnight bacterial broth culture $\left(10 \mu \mathrm{l} \mathrm{ml}^{-1}\right)$ was added to each RBC monolayer and the dishes were incubated for $4 \mathrm{~h}$ at $37^{\circ} \mathrm{C}$. Non-attached bacteria were removed by washing three times in PBS and the monolayers were fixed in either formaldehyde (for immunofluorescence) or glutaraldehyde (for electron microscopy).

Antibodies and fluorescent stains. Polyclonal rabbit antibody to the N-terminal region (TirN) or intimin-binding domain of Tir (TirM) (Hartland et al., 1999) were used for microscopical studies; a Tir mAb was used for Western blotting studies (Hartland et al., 1999). Polyclonal rabbit antibody to EspA was used to stain EspA filaments (Knutton et al., 1998). Polyclonal mouse antibody to the cell-binding domain of intimin $\left(\mathrm{Int}_{280}\right)$ was used to stain intimin (Hartland et al., 1999). G410 tyrosine phosphate mAb (Upstate Technology) was used to examine Tir tyrosine phosphorylation. Rhodamine-conjugated wheat germ agglutinin (Sigma) was used to stain the RBC membrane (red). FITC-conjugated phalloidin (Sigma) was used to stain cytoskeletal actin (green). 4,6-Diamidino-2phenylindole (DAPI; Molecular Probes) was used to stain bacterial DNA (blue). Fluorescent second antibodies used were Alexa488- (green) and Alexa594- (red) conjugated goat antirabbit IgG or goat anti-mouse IgG conjugates (Molecular Probes).

Immunofluorescence microscopy. To stain Tir with the TirN and phosphotyrosine antibodies, and RBC cytoskeletal actin, RBCs were permeabilized with PBS containing $0 \cdot 1 \%$ Triton $\mathrm{X}-100$ for $5 \mathrm{~min}$ and washed three times in PBS. All antibody dilutions and immune reactions were carried out in PBS containing $0 \cdot 2 \%$ bovine serum albumin (PBS-BSA). Formalinfixed, permeabilized and washed RBC monolayers were incubated with antiserum (generally $1: 50-1: 100$ ) in PBS-BSA for $45 \mathrm{~min}$ at room temperature. After three $5 \mathrm{~min}$ washes in PBS samples were stained with either Alexa488- or Alexa594conjugated goat anti-rabbit $\operatorname{IgG}$ or goat anti-mouse $\operatorname{IgG}$ (Molecular Probes) diluted 1:50 in PBS-BSA for $45 \mathrm{~min}$; in most experiments samples were simultaneously stained with rhodamine-conjugated wheat germ agglutinin to visualize the RBC membrane, and with DAPI to stain bacteria. Preparations were washed a further three times in PBS, mounted in glycerolPBS and examined by incident light fluorescence using a Leica DMR microscope equipped with a DC200 digital camera. In multi-labelling studies individual red (Alexa594, rhodamine), green (Alexa488) and/or blue (DAPI) images were superimposed using Leica IM1000 software. Confocal microscopy was performed using a Leica TCS SP2 Spectral Confocal Microscope.

Electron microscopy. For immunogold Tir and intimin labelling, RBC monolayers on plastic culture dishes were briefly fixed for $10 \mathrm{~min}$ in $0.1 \%$ glutaraldehyde, washed three times with PBS, permeabilized in $0 \cdot 1 \%$ Triton X-100 for $5 \mathrm{~min}$ and washed a further three times in PBS. Monolayers were incubated with TirN and intimin antisera $(1: 100)$ for $4 \mathrm{~h}$ at room temperature, washed three times in PBS-BSA and incubated with $5 \mathrm{~nm}$ gold-labelled goat anti-rabbit serum and $10 \mathrm{~nm}$ gold-labelled goat anti-mouse serum (British Biocell) for $12 \mathrm{~h}$ at $4{ }^{\circ} \mathrm{C}$. After further thorough washing, cells were scraped from the dish, pelleted, fixed in $3 \%$ buffered glutaraldehyde and processed for thin-section electron microscopy using standard procedures (Knutton, 1995). Ultrathin sections were examined in a JEOL 1200EX electron microscope operated at $80 \mathrm{kV}$.

For scanning electron microscopy EPEC-infected RBC monolayers prepared on glass cover slips were fixed with $3 \%$ glutaraldehyde, post-fixed in $1 \%$ osmium tetroxide, dehydrated through graded alcohol solutions and critical-pointdried. For immunogold labelling, monolayers were briefly fixed for $10 \mathrm{~min}$ in $0.1 \%$ glutaraldehyde, washed, incubated 
Table 1. List of strains used and their ability to translocate and focus Tir

\begin{tabular}{|c|c|c|c|}
\hline Strain & Description & Reference & Tir focusing* \\
\hline E2348/69 & Wild-type EPEC O127:H6 & Levine et al. (1978) & $+/(+++++)$ \\
\hline CVD206 & $\mathrm{E} 2348 / 69$ eae & Jerse et al. (1990) & - \\
\hline UMD872 & E2348/69 espA & Kenny et al. (1996) & - \\
\hline UMD870 & $\mathrm{E} 2348 / 69$ espD & Lai et al. (1997) & - \\
\hline UMD864 & $\mathrm{E} 2348 / 69$ espB & Donnenberg et al. (1993) & - \\
\hline CVD452 & $\mathrm{E} 2348 / 69 \operatorname{esc} \mathrm{N}$ & Jarvis et al. (1995) & - \\
\hline SE896 & E2348/69 tir & Elliott et al. (1999) & - \\
\hline SE884 & $\mathrm{E} 2348 / 69$ ces $\mathrm{T}$ & Elliott et al. (1999) & - \\
\hline \multicolumn{4}{|l|}{ Co-culture infections } \\
\hline CVD206: UMD872 & & & ++++ \\
\hline E2348/69: UMD872 & & & ++++ \\
\hline UMD870: UMD872 & & & - \\
\hline UMD864:UMD872 & & & + \\
\hline SE896: UMD872 & & & - \\
\hline SE884: UMD872 & & & - \\
\hline
\end{tabular}

* Bacteria were grown from frozen stocks and semi-quantitative assessment of Tir focusing followed a $4 \mathrm{~h}$ infection of RBCs : $0(-)$ to $100 \%(+++++)$ cells possessing focused Tir.

† Bacteria passaged daily for 4 days.

with intimin antiserum $(1: 100)$ for $4 \mathrm{~h}$ at room temperature, washed again and incubated with $30 \mathrm{~nm}$ gold-labelled goat anti-mouse serum $(1: 100)$ for $12 \mathrm{~h}$. After further thorough washing, cells were fixed in $3 \%$ buffered glutaraldehyde and processed as described above. Mounted specimens were sputter-coated with platinum (Polaron) and examined in a JEOL 1200EX Scanning Transmission Electron Microscope.

RBC membrane preparation. The method for membrane isolation was adapted from Blocker et al. (1999). RBCs were sedimented, washed three times in PBS and resuspended in PBS at approximately $5 \times 10^{8}$ cells $\mathrm{ml}^{-1}$. Washed RBCs $(2 \mathrm{ml})$ were then mixed with $0.4 \mathrm{ml}$ UMD872 and CVD206 in a mixed infection, and $0.4 \mathrm{ml}$ CVD456 as a negative control. PBS $(2.4 \mathrm{ml})$ was added to each infection and the infections incubated at $37^{\circ} \mathrm{C}$ for $6 \mathrm{~h}$. Distilled water $(0 \cdot 8 \mathrm{ml})$ was then added to obtain equal lysis of each infection. The samples were vortexed and spun to pellet any unlysed RBCs. Supernatant $(3.4 \mathrm{ml})$ was then mixed with $6 \mathrm{ml} 72 \%$ sucrose and transferred to SW40 centrifuge tubes. The mixtures were then overlaid with $2 \mathrm{ml} 42 \%$ sucrose and $1 \mathrm{ml} 25 \%$ sucrose, and the sucrose cushions were spun at $15000 \mathrm{~g}$ for $16 \mathrm{~h}$. The RBC membranes were collected from the interface between the 42 and $25 \%$ sucrose layers and spun at $450000 \mathrm{~g}$ for $30 \mathrm{~min}$ at $4{ }^{\circ} \mathrm{C}$. The pellets were resuspended in $15 \mu \mathrm{l}$ SDS gel loading buffer.

E2348/69 whole-cell lysate preparation. An overnight culture of E2348/69 was diluted 1:100 into DMEM and grown with shaking at $37^{\circ} \mathrm{C}$ for $4 \mathrm{~h}$. A sample $(1.5 \mathrm{ml})$ of culture was spun in a microfuge $(15000 \mathrm{~g})$ for $5 \mathrm{~min}$ to pellet the bacteria. The supernatant was discarded and the bacterial cell pellet was resuspended in $100 \mu \mathrm{l}$ gel loading buffer.

Immunoblotting. A sample $(15 \mu \mathrm{l})$ of the $\mathrm{RBC}$ membrane preparation from the UMD872/CVD206 infection, together with $15 \mu$ l whole-cell lysate from E2348/69 were separated by SDS-PAGE on a $12 \%$ gel run for $1 \mathrm{~h}$ at $180 \mathrm{~V}$ in a Bio-Rad mini-PROTEAN II cell. Proteins were transferred to a nitrocellulose membrane using a Bio-Rad mini-trans blot apparatus run for $45 \mathrm{~min}$ at $100 \mathrm{~V}$. The membrane was blocked with $10 \%$ skimmed milk in PBS, $0.05 \%$ Tween-20 for $1 \mathrm{~h}$ and then washed four times in PBS-Tween. It was then incubated overnight at $4{ }^{\circ} \mathrm{C}$ with anti-Tir mAb diluted 1:100 in PBS-Tween (Hartland et al., 1999). The blots were washed and detected with anti-mouse alkaline-phosphataseconjugated antibody as described previously (Knutton et al., 1998).

\section{RESULTS}

\section{Tir is translocated into RBC membranes}

We previously demonstrated EspA filament-mediated attachment of EPEC to RBCs and translocation of EspD to the RBC membrane (Shaw et al., 2001). However, bacteria forming intimate contact with RBCs were not observed. Consistent with this, we failed to detect, by Western blotting, Tir translocation to the RBC membrane (Shaw et al., 2001). Possible reasons for the lack of intimate bacterial attachment were (a) Tir translocation did not occur, (b) Tir translocation did occur but Tir was not inserted into the RBC membrane, or (c) Tir translocation and membrane insertion did occur, but Tir was unable to bind intimin to form an intimate bacterial attachment.

To detect Tir in this study we used fluorescence microscopy and an antibody to the $\mathrm{N}$-terminal region of the Tir molecule (TirN antibody), a part of the molecule that is exposed, following translocation, on the cytoplasmic face of the plasma membrane (Hartland et al., 1999). Examination of RBC monolayers infected with wild-type EPEC strain E2348/69 for $4 \mathrm{~h}$ revealed, in a small number of RBCs, thin bands of fluorescence 

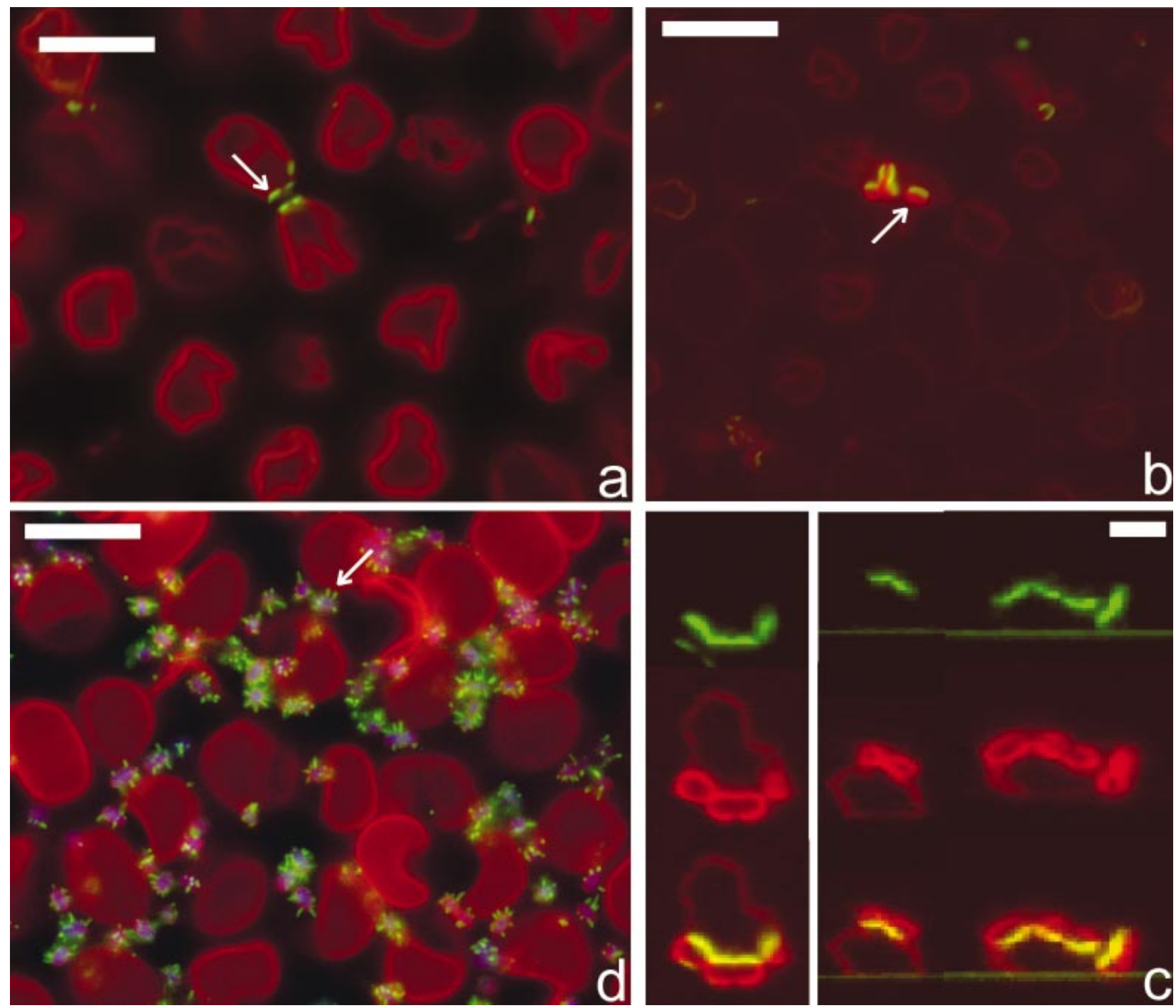

Fig. 1. Fluorescence images following a $4 \mathrm{~h}$ infection of RBC monolayers with EPEC strain E2348/69. Thin bands of Tir staining (green) (a, arrow) were seen in a small fraction of RBCs (red). Bacteria associated with focused Tir (green) expressed surface intimin (red) (b, arrow). Confocal $x y$ (c, left column) and $x z$ sections ( $c$, right column) showing focused Tir (top, green), intimin-expressing bacteria (bright red) adhering to the RBC membrane (dull red, centre) and in the superimposed images co-localization of Tir and the RBC membrane and Tir and intimin (bottom). Many other celladherent bacteria (blue) not associated with Tir did not express intimin but expressed EspA filaments (green) which promoted their attachment to RBCs (red) (d, arrow). Scale bars: a-c, $10 \mu \mathrm{m} ; \mathrm{d}, 0.5 \mu \mathrm{m}$.

staining reminiscent of Tir staining seen in typical A/E lesions (Fig. 1a). Double staining for Tir and intimin confirmed that such fluorescence was indeed Tir that was focused beneath bacteria expressing surface intimin (Fig. 1b); co-localization of Tir and intimin, and Tir and the RBC membrane demonstrated by confocal microscopy (Fig. 1c) was consistent with Tir translocation to the RBC membrane and intimin-Tir intimate attachment. By fluorescence microscopy we were unable to detect unfocused Tir in E2348/69-infected RBC membranes (data not shown). However, a general bacterial stain revealed many adherent bacteria most of which were not associated with focused Tir and, significantly, did not express surface intimin; attachment of these intimin-negative bacteria to the RBCs was mediated, as described previously (Shaw et al., 2001), by EspA filaments (Fig. 1d). These results demonstrate that EPEC can translocate Tir into the RBC membrane.

\section{Intimin binding stabilizes translocated Tir}

The above data also suggest that a lack of intimin expression by the majority of adherent bacteria may be the reason for the very low level of intimate bacterial attachment. To test this and examine further the importance of Tir translocation and/or surface intimin expression in intimate EPEC attachment to RBCs, we performed co-culture infections using one strain known 

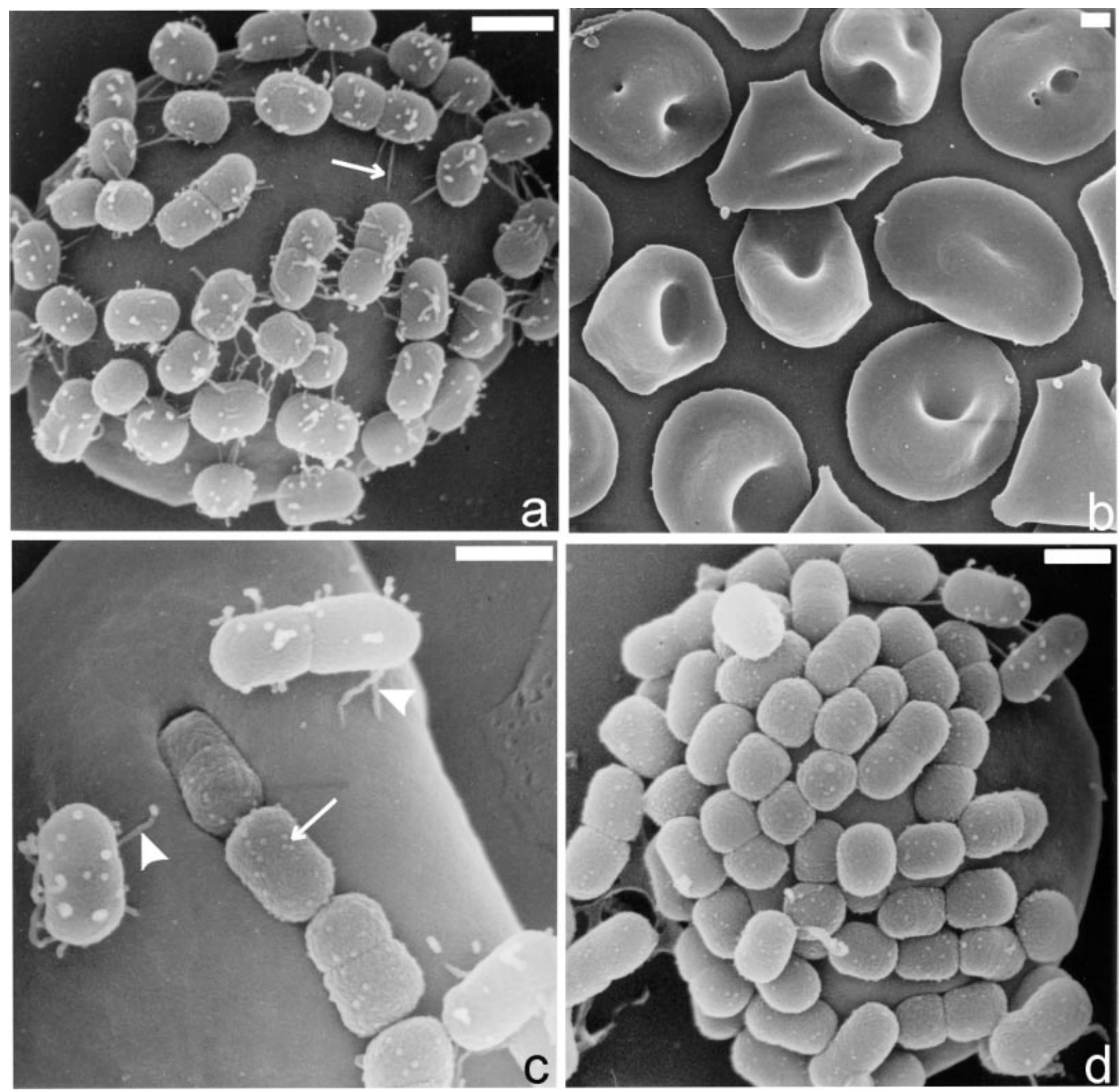

Fig. 2. Scanning electron micrographs following a $4 \mathrm{~h}$ infection of RBC monolayers with CVD206 (a), UMD872 (b) and a $4 \mathrm{~h}$ co-infection with CVD206/UMD872 (c, d). CVD206 exhibited EspA filament-mediated attachment to RBCs (a, arrow), whereas UMD872 was non-adherent (b). In co-infections, CVD206 was identified by EspA filaments (c, arrowheads) and UMD872 by a lack of EspA filaments and immunogold-labelled intimin (c, arrow). After $4 \mathrm{~h}$ most RBCs were covered predominantly with intimately attached UMD872 bacteria (d). Scale bars, $0.5 \mu \mathrm{m}$.

to translocate Tir into host cells (eae intimin mutant strain CVD206) (Rosenshine et al., 1996) and a second strain known to express surface intimin strongly, but which cannot translocate Tir (espA mutant strain UMD872). These strains were also selected because they could easily be distinguished microscopically in coculture infections: CVD206 by the presence of EspA filaments and UMD872 by the presence of surface intimin. In single infection experiments with these strains scanning electron microscopy revealed EspA filament-mediated attachment of CVD206 bacteria to RBCs (Fig. 2a), whereas strain UMD872, which does not produce EspA filaments, was non-adherent (Fig. 2b). In co-infections, CVD206 could be identified by EspA filaments (Fig. 2c, arrowhead) and UMD872 by an absence of EspA filaments and presence of gold-labelled intimin (Fig. 2c, arrow). Noticeably, UMD872 bacteria were now adherent and displayed what appeared to be an intimate attachment to the RBC membrane (Fig. 2c). After a $4 \mathrm{~h}$ co-infection most cells were predominantly 

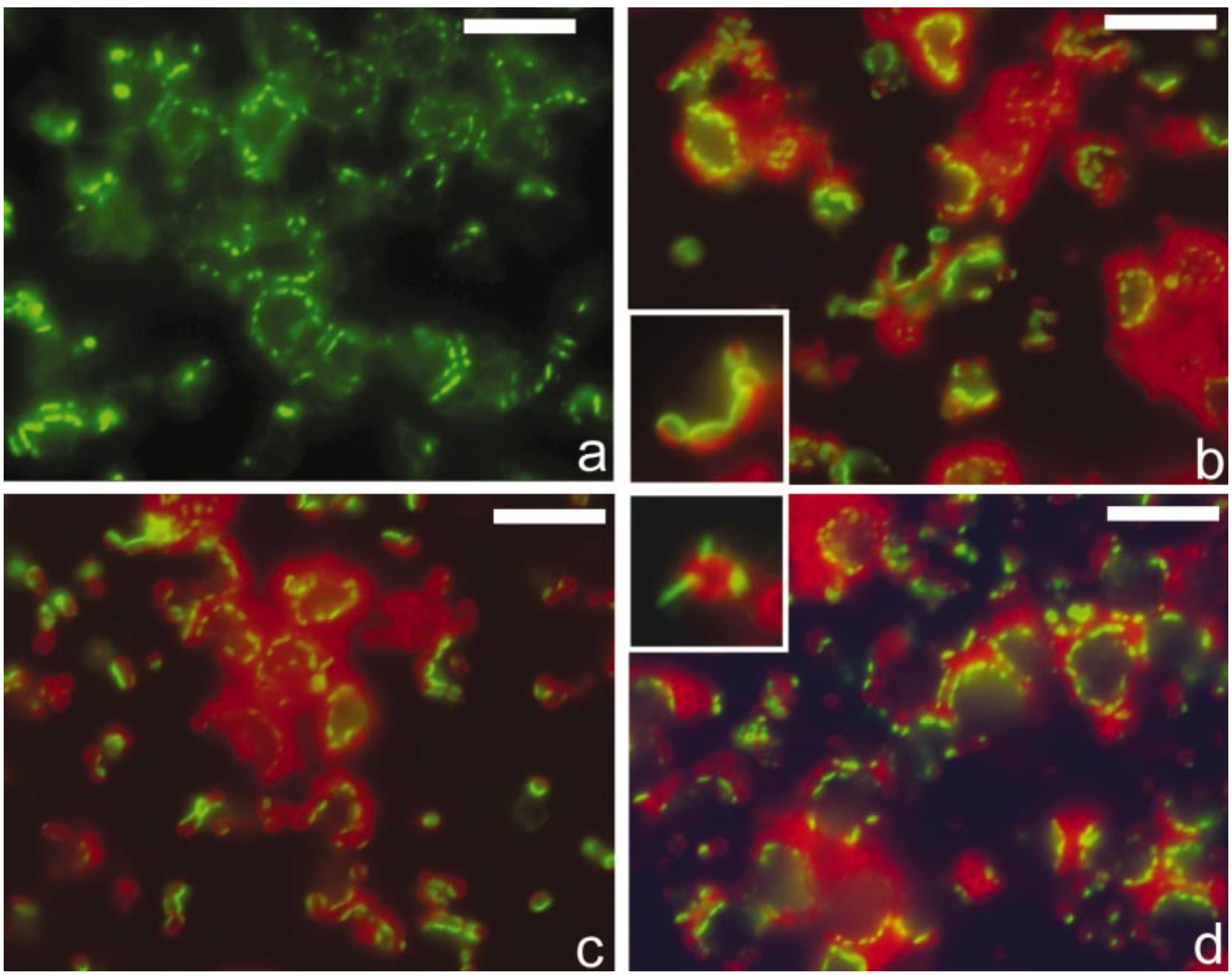

Fig. 3. Fluorescence micrographs illustrating highly efficient Tir translocation and focusing in co-infected (a-c) and singly infected RBC monolayers (d). Tir is stained green and intimin red. Focused Tir was present in most RBCs co-infected for $4 \mathrm{~h}$ with CVD206 and UMD872 (a) and was focused beneath intimin-expressing UMD872 bacteria (b and inset). Efficient Tir focusing was also observed following E2348/69/UMD872 co-infections (c) and following a single infection with serially passaged E2348/69 (d); prior to intimate attachment, serially passaged bacteria were now seen to express surface intimin (red) and to adhere to RBCs by EspA filaments (green) (d, inset). Scale bars, $10 \mu \mathrm{m}$.

covered with intimately attached UMD872 bacteria with only a few CVD206 bacteria detectable (Fig. 2d).

The fact that UMD872 bacteria were intimately attached and that intimate attachment resulted from Tir translocation and intimin-Tir interaction was confirmed by fluorescence and electron microscopy. Following CVD206/UMD872 co-infections, extensive Tir fluorescence was seen associated with most RBCs (Fig. 3a), and double staining for Tir and intimin confirmed that such Tir fluorescence was focused beneath intiminexpressing UMD872 bacteria (Fig. 3b). An intimate intimin-Tir interaction characteristic of that seen in $\mathrm{A} / \mathrm{E}$ lesions was also confirmed by transmission electron microscopy. RBC monolayers co-infected with CVD206 and UMD872 for $4 \mathrm{~h}$ were immunostained for Tir using the TirN antibody and $5 \mathrm{~nm}$ gold, and for intimin with a mouse intimin antibody and $10 \mathrm{~nm}$ gold. Sectioned
RBC preparations revealed an intimate attachment of UMD872 bacteria with Tir staining of the RBC membrane only at sites of intimate attachment (Fig. 4a, b). At higher magnification when the RBC membrane was cross-sectioned Tir labelling with the TirN antibody was clearly seen to occur specifically at the cytoplasmic surface of the RBC membrane (Fig. 4c). Intimin staining was seen over the exposed bacterial surface but, as reported previously (Knutton et al., 1997), no intimin staining was seen at the actual site of intimate attachment, presumably because the intimin antibody, which binds the extracellular domain of intimin, cannot penetrate into the region of intimate attachment and/or bind intimin once it is already tightly bound to Tir (Fig. 4c).

Having confirmed that CVD206 was capable of efficient Tir translocation to RBC membranes and the presence 


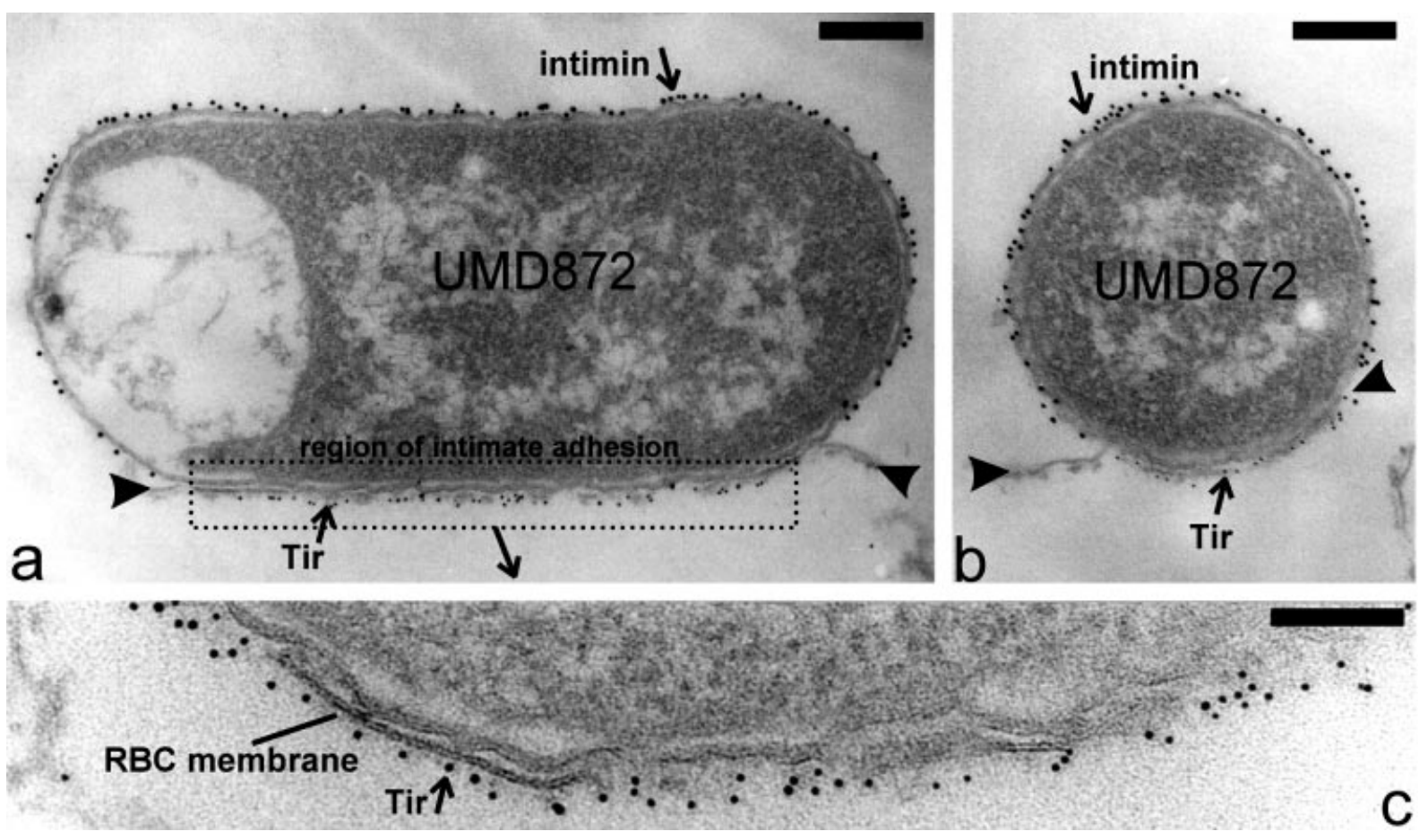

Fig. 4. Transmission electron micrographs showing immunogold-labelled Tir and intimin following a $4 \mathrm{~h}$ co-infection of RBCs with CVD206/UMD872. UMD872 bacteria, identified by surface intimin stained with $10 \mathrm{~nm}$ gold (a, b), formed intimate attachment to the RBC membrane ( $a, b$, arrowheads). Tir stained with $5 \mathrm{~nm}$ gold was localized to the cytoplasmic surface of the RBC membrane, only at the site of intimate bacterial attachment (c). Scale bars: $a, b, 0.2 \mu \mathrm{m} ; \mathrm{c}$, $0 \cdot 1 \mu \mathrm{m}$.

of surface intimin on UMD872 stabilized and focused translocated Tir, we performed similar co-culture experiments to examine Tir translocation by wild-type EPEC strain E2348/69 and defined E2348/69 mutants. When wild-type E2348/69 was co-infected with strain UMD872 we observed a similar dramatic increase in intimate bacterial attachment and Tir focusing (Fig. 3c), demonstrating that the wild-type strain was capable of efficient Tir translocation to the RBC membrane. As expected, no Tir translocation and intimate attachment occurred when UMD872 was co-infected with tir, cesT and espD mutant strains (Table 1) but, interestingly, Tir translocation and intimate attachment was occasionally seen when $e s p B$ mutant strain UMD864 was co-infected with UMD872 (data not shown), demonstrating that there is not an absolute requirement of EspB for Tir translocation.

\section{Optimization of EPEC infection of RBCs}

Tir and intimin are believed to be expressed from a single operon (tir) (Mellies et al., 1999). Nevertheless, the co-infection studies showed that wild-type E2348/69 could translocate Tir efficiently into the RBC membrane (Fig. 3c), even in the absence of detectable surface intimin expression (Fig. 1d). This, therefore, is the most likely explanation for the low level of intimate attachment initially observed (Fig. 1b). Routinely, we grew bacteria in Luria broth from frozen stock cultures. Since such cultures yielded very low levels of intimate bacterial attachment we investigated other growth conditions to try to modulate intimin expression. Interestingly, serial passaging of E2348/69 in Luria broth for several days resulted in intimin being expressed on the surface of all the RBC-adherent bacteria (Fig. 3d, inset). Now a 4 h infection of RBCs with E2348/69 that had been serially passaged daily for 4 days yielded levels of intimate intimin-Tir attachment comparable to those obtained during the co-infection experiments with most RBCs covered with intimately attached bacteria (Fig. $3 \mathrm{~d})$.

Using these optimized infection conditions, examination of defined E2348/69 mutants showed that Tir translocation into the RBC membrane, as for epithelial cell membranes, was dependent on the Tir chaperone, Ces T, on a functional type III secretion apparatus and on secreted proteins EspA and EspD; surface intimin expression was required to focus Tir (Table 1).

\section{Translocated Tir does not undergo host-cell modification}

In EPEC-infected epithelial cells translocated Tir becomes phosphorylated on tyrosine residues (Rosenshine et al., 1992), an event essential for the subsequent interaction with the host-cell cytoskeleton and A/E 

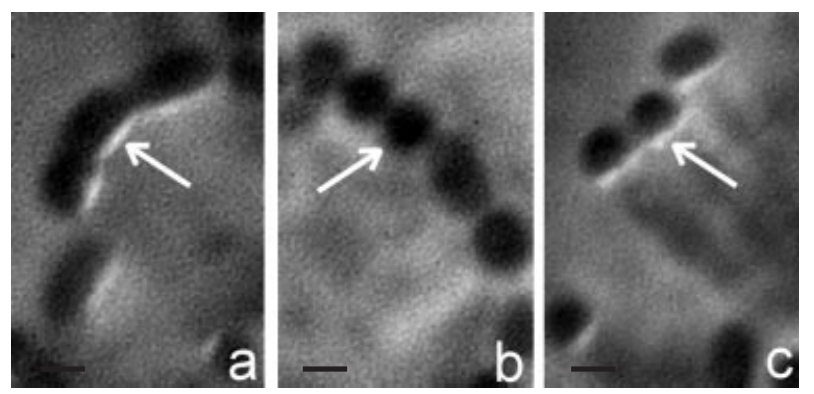

Fig. 5. Fluorescence micrographs following $4 \mathrm{~h}$ co-infections of RBC (a, b) and HEL cell monolayers (c) with CVD206 and UMD872. Focused Tir was seen beneath bacteria intimately attached to RBCs (a, arrow), but there was no tyrosine phosphorylation of Tir (b, arrow). Tyrosine-phosphorylated Tir was seen in infected HEL cells (c, arrow). Scale bars, $0.5 \mu \mathrm{m}$.

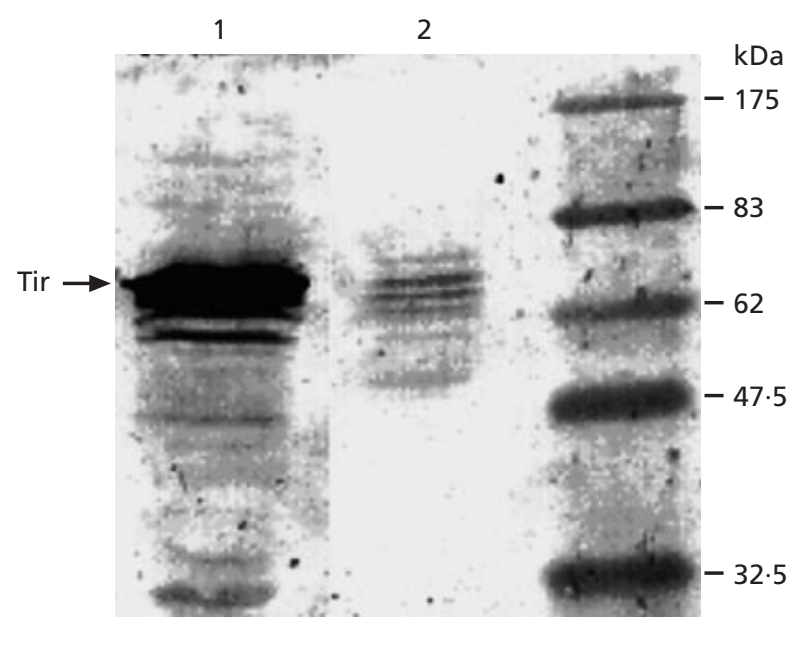

Fig. 6. Analysis of bacterial Tir and RBC-membrane-associated Tir following $4 \mathrm{~h}$ co-infections. Tir was detected using monoclonal Tir antiserum (arrow). Tir, with an apparent molecular mass of $\sim 78 \mathrm{kDa}$ was associated with E2348/69 whole-cell lysate (lane 1) and RBC membranes co-infected with strains CVD206/UMD872 (lane 2). Molecular mass markers (kDa) are indicated.

lesion formation (Kenny, 1999). In RBCs we were able to detect focused Tir using the TirN antibody and fluorescence staining (Fig. 5a), but using a tyrosine phosphate antibody we were unable to detect tyrosine phosphorylation of translocated and focused Tir (Fig. $5 \mathrm{~b})$; in contrast, using the same antibody, tyrosinephosphorylated Tir focused beneath intimately attached bacteria was readily detected in E2348/69-infected epithelial (HEL) cells (Fig. 5c).

In epithelial cells, Tir translocation and intimin-Tir interaction results in cytoskeletal accretion, actin polymerization and pedestal formation beneath intimately attached bacteria. There was no pedestal formation in RBCs, although it was possible that, following intiminTir interaction, Tir might interact with and focus components of the RBC cytoskeleton. In this study we performed fluorescence actin staining to determine if RBC cytoskeletal actin became focused beneath intimately attached bacteria. A very weak and uniform actin fluorescence was observed with uninfected RBCs and this was unchanged following a $4 \mathrm{~h}$ co-infection with strains CVD206 and UMD872 (data not shown).

By Western blotting we were previously unable to detect translocated Tir (Shaw et al., 2001). In this study we performed Western blots using a Tir mAb on wild-type EPEC cell lysates and following a $4 \mathrm{~h}$ co-culture infection of RBCs with strains CVD206 and UMD872. Tir with an apparent molecular mass of $\sim 78 \mathrm{kDa}$ was detected both in bacteria and in fractionated RBC membranes (Fig. 6); no RBC membrane-associated Tir was detected in a control co-infection using the type III secretion mutant CVD452 and UMD872, whilst Tir detected in infected Hep-2 cell membranes migrated with an apparent molecular mass of $85 \mathrm{kDa}$, as reported by Kenny (1999) and Kenny \& Finlay (1997) (data not shown).

\section{DISCUSSION}

While RBCs represent a poor in vitro cell model of EPEC pathogenesis in general, they do nevertheless represent a useful model to examine specific aspects of EPEC-host cell interaction such as type III protein translocation. Using a static infection of RBC monolayers, this study has shown that the EPEC effector protein, Tir, is translocated and correctly inserted into the RBC membrane and can interact with surface-expressed intimin to produce an intimate bacterial attachment typical of that seen in $\mathrm{A} / \mathrm{E}$ lesions.

During A/E lesion formation Tir is translocated to the host-cell membrane by the LEE type III secretion apparatus where it acts as a receptor for intimin; intimin-Tir binding results in Tir becoming focused beneath intimately attached bacteria (Rosenshine et al., 1996). We have proposed a model for the EPEC type III protein translocation apparatus used to translocate Tir which consists of pores in the bacterial and host-cell membranes connected by a hollow EspA filament (Frankel et al., 1998), thereby providing a continuous channel from the bacterial to the host-cell cytosol. Such a model is consistent with our previously observed interaction of EPEC with RBCs (Shaw et al., 2001) which demonstrated EspA-filament-mediated interaction of EPEC with the RBC membrane, RBC haemolysis and localization of $\mathrm{EspD}$, a putative pore-forming type III secreted protein, to the RBC membrane. However, our inability to demonstrate membraneassociated Tir suggested that effector protein translocation or membrane insertion might not occur in this RBC model.

Using immunofluorescence and immunoelectron microscopy, this study has now demonstrated that Tir is translocated and correctly inserted into the RBC membrane where it can bind intimin expressed on the bacterial surface to produce an intimate bacterial attachment characteristic of that seen in A/E lesions. 
Initially we observed very low levels of intimate intiminTir attachment which could have resulted from lack of Tir translocation and/or lack of intimin expression. The co-infection experiments showed that wild-type E2348/69 can translocate Tir efficiently to the RBC membrane, since UMD872 is unable to secrete or translocate Tir (Kenny et al., 1996; Knutton et al., 1998). Single infection experiments using E2348/69 grown from frozen stocks suggested that the initially observed low levels of intimate attachment might be due to a lack of surface intimin expression for Tir to bind to and this was confirmed using serially passaged bacteria ; adherent bacteria now expressed surface intimin and were able to efficiently form an intimate intimin-Tir attachment. In a previous study by Western blotting (Shaw et al., 2001) and in this study by fluorescence staining we were unable to detect unfocused Tir in the RBC membrane which suggests that, in the absence of intimin binding, translocated Tir is unstable and is either degraded or lost from the membrane. Considering the fact that following natural infections both $\operatorname{IgA}$ and $\operatorname{IgG}$ Tir antibodies are produced (Jenkins et al., 2000; Li et al., 2000), elimination of exposed, unbound Tir from the plasma membrane would be expected to benefit both the bacterium and the host. The reason for the observed difference in intimin expression between fresh and passaged E2348/69 cultures is not clear. Given that Tir and intimin are encoded on the same operon, one would expect both proteins to be co-translated. Either this is not necessarily the case, and there is some evidence that intimin might be expressed from its own promoter in addition to the promoter that transcribes it as part of the tir operon (Gomez-Duarte \& Kaper, 1995), or alternatively, some post-transcriptional regulation of intimin might be involved.

The mechanism of protein translocation has yet to be fully elucidated for any type III secretion system (Hueck, 1998). In the case of type III translocated integral membrane proteins such as Tir there are two likely mechanisms for Tir insertion into the host-cell membrane; direct translocation into the host-cell membrane by the type III machinery or translocation into the hostcell cytosol followed by insertion into the cell membrane. Kenny (1999) has proposed that Tir is first translocated into the host cytosol where it undergoes host-cell modifications followed by insertion into the membrane; these host-cell modifications have now been shown to involve Tir phosphorylation on two serine residues (S434 and S463) by protein kinase A, giving rise to $\sim 5$ and $\sim 2 \mathrm{kDa}$ increases in Tir apparent molecular mass, respectively (Warawa \& Kenny, 2001). It is proposed that the sequential addition of these two phosphate groups may trigger conformational changes in Tir structure that might supply the energy to insert cytosolic Tir into the cell membrane. These studies were carried out following a $4 \mathrm{~h}$ infection of HeLa cells. In contrast, Gauthier et al. (2000) detected Tir in cell membrane fractions after $1.5 \mathrm{~h}$, but only in the cytosolic fraction at very late time points, suggesting that Tir is most likely translocated directly into the host-cell membrane. In the present study it is clear from the fluorescence studies that large amounts of Tir have become translocated to the RBC membrane, and since only Tir, with an apparent molecular mass of $\sim 78 \mathrm{kDa}$, was observed, it can be concluded that Tir detected in the RBC membrane by immunofluorescence and by Western blotting had undergone neither tyrosine nor serine phosphorylation, since there was no Tir staining with a tyrosine kinase antibody and no apparent increase in Tir molecular mass from 78 to $85 \mathrm{kDa}$. Tir with an apparent molecular mass of $\sim 85 \mathrm{kDa}$, typical of that seen following infection of epithelial cells (Kenny, 1999; Kenny \& Finlay, 1997), would have been detected in the Western blots had it been present. RBCs, therefore, due to the lack of appropriate serine and tyrosine kinases, appear to provide an infection model that allows Tir translocation to be separated from hostcell Tir modifications. This lack of Tir modification following translocation to the RBC membrane suggests that native unmodified Tir is inserted directly into the host-cell membrane by the type III secretion system and that host-cell Tir modifications occur subsequent to membrane insertion.

Following insertion into the host-cell membrane, EPEC Tir becomes phosphorylated on tyrosine residues, a requirement for the subsequent actin nucleating activity of Tir and A/E lesion formation (Kenny, 1999). Tir was recently shown to interact directly with $\alpha$-actinin which is proposed to provide the linkage between Tir and the actin cytoskeleton (Goosney et al., 2000). We were unable to demonstrate tyrosine phosphorylation of translocated Tir, and $\alpha$-actinin is not a component of the $\mathrm{RBC}$ cytoskeleton. Thus, although translocated Tir can be focused as a result of intimin binding, it is not surprising that in RBCs there was no actin accretion or pedestal formation.

\section{ACKNOWLEDGEMENTS}

We thank Jim Kaper, Simon Elliott and Michael Donnenberg from the Center for Vaccine Development, University of Maryland, for providing E2348/69 derivatives and plasmids, and Mrs Ania Straatman for excellent technical assistance. This work was supported by the Wellcome Trust.

\section{REFERENCES}

Blocker, A., Gounon, P., Larquet, E., Niebuhr, K., Cabiaux, V., Parsot, C. \& Sansonetti, P. (1999). The tripartite type III secretion of Shigella flexneri inserts IpaB and IpaC into host membranes. $J$ Cell Biol 147, 683-693.

Clerc, P., Baudry, B. \& Sansonetti, P. J. (1986). Plasmid-mediated contact haemolytic activity in Shigella species: correlation with penetration into HeLa cells. Ann Inst Pasteur Microbiol 137A, 267-278.

Donnenberg, M. S., Yu, J. \& Kaper, J. B. (1993). A second chromosomal gene necessary for intimate attachment of enteropathogenic Escherichia coli to epithelial cells. J Bacteriol 175, 4670-4680.

Elliott, S. J., Hutcheson, S. W., Dubois, M. S., Mellies, J. L., Wainwright, L. A., Batchelor, M., Frankel, G., Knutton, S. \& 
Kaper, J. B. (1999). Identification of CesT, a chaperone for the type III secretion of Tir in enteropathogenic Escherichia coli. Mol Microbiol 33, 1176-1189.

Frankel, G., Phillips, A. D., Rosenshine, I., Dougan, G., Kaper, J. B. \& Knutton, S. (1998). Enteropathogenic and enterohaemorrhagic Escherichia coli: more subversive elements. Mol Microbiol 30, 911-921.

Gauthier, A., de Grado, M. \& Finlay, B. B. (2000). Mechanical fractionation reveals structural requirements for enteropathogenic Escherichia coli Tir insertion into host membranes. Infect Immun 68, 4344-4348.

Gomez-Duarte, O. G. \& Kaper, J. B. (1995). A plasmid-encoded regulatory region activates chromosomal eaeA expression in enteropathogenic Escherichia coli. Infect Immun 63, 1767-1776.

Goosney, D. L., DeVinney, R., Pfuetzner, R. A., Frey, E. A., Strynadka, N. C. \& Finlay, B. B. (2000). Enteropathogenic E. coli translocated intimin receptor, Tir, interacts directly with alphaactinin. Curr Biol 10, 735-738.

Hakansson, S., Schesser, K., Persson, C., Galyov, E. E., Rosqvist, R., Homble, F. \& Wolf-Watz, H. (1996). The YopB protein of Yersinia pseudotuberculosis is essential for the translocation of Yop effector proteins across the target cell plasma membrane and displays a contact-dependent membrane disrupting activity. EMBO J 15, 5812-5823.

Hartland, E. L., Batchelor, M., Delahay, R. M., Hale, C., Matthews, S., Dougan, G., Knutton, S., Connerton, I. \& Frankel, G. (1999). Binding of intimin from enteropathogenic Escherichia coli to Tir and to host cells. Mol Microbiol 32, 151-158.

Hueck, C. J. (1998). Type III protein secretion systems in bacterial pathogens of animals and plants. Microbiol Mol Biol Rev 62, $379-433$.

Jarvis, K. G., Giron, J. A., Jerse, A. E., McDaniel, T. K., Donnenberg, M. S. \& Kaper, J. B. (1995). Enteropathogenic Escherichio coli contains a putative type III secretion system necessary for the export of proteins involved in attaching and effacing lesion formation. Proc Natl Acad Sci U S A 92, 7996-8000.

Jenkins, C., Chart, H., Smith, H. R., Hartland, E. L., Batchelor, M., Delahay, R. M., Dougan, G. \& Frankel, G. (2000). Antibody response of patients infected with verocytotoxin-producing Escherichia coli to protein antigens encoded on the LEE locus. J Med Microbiol 49, 97-101.

Jerse, A. E., Yu, J., Tall, B. D. \& Kaper, J. B. (1990). A genetic locus of enteropathogenic Escherichia coli necessary for the production of attaching and effacing lesions on tissue culture cells. Proc Natl Acad Sci U S A 87, 7839-7843.

Kenny, B. (1999). Phosphorylation of tyrosine 474 of the enteropathogenic Escherichia coli (EPEC) Tir receptor molecule is essential for actin nucleating activity and is preceded by additional host modifications. Mol Microbiol 31, 1229-1241.

Kenny, B. \& Finlay, B. B. (1997). Intimin-dependent binding of enteropathogenic Escherichia coli to host cells triggers novel signaling events, including tyrosine phosphorylation of phospholipase C-gamma1. Infect Immun 65, 2528-2536.

Kenny, B. \& Jepson, M. (2000). Targeting of an enteropathogenic E. coli (EPEC) effector protein to host mitochondria. Cell Microbiol 2, 579-590.

Kenny, B., Lai, L. C., Finlay, B. B. \& Donnenberg, M. S. (1996). EspA, a protein secreted by enteropathogenic Escherichia coli, is required to induce signals in epithelial cells. Mol Microbiol $\mathbf{2 0}$, 313-323.

Kenny, B., DeVinney, R., Stein, M., Reinscheid, D. J., Frey, E. A. \& Finlay, B. B. (1997). Enteropathogenic E. coli (EPEC) transfers its receptor for intimate adherence into mammalian cells. Cell 91, 511-520.

Knutton, S. (1995). Electron microscopical methods in adhesion. Methods Enzymol 253, 145-158.

Knutton, S., Lloyd, D. R. \& McNeish, A. S. (1987). Adhesion of enteropathogenic Escherichia coli to human intestinal enterocytes and cultured human intestinal mucosa. Infect Immun 55, 69-77.

Knutton, S., Baldwin, T., Williams, P. H. \& McNeish, A. S. (1989). Actin accumulation at sites of bacterial adhesion to tissue culture cells: basis of a new diagnostic test for enteropathogenic and enterohemorrhagic Escherichia coli. Infect Immun 57, 1290-1298.

Knutton, S., Adu-Bobie, J., Bain, C., Phillips, A. D., Dougan, G. \& Frankel, G. (1997). Down regulation of intimin expression during attaching and effacing enteropathogenic Escherichia coli adhesion. Infect Immun 65, 1644-1652.

Knutton, S., Rosenshine, I., Pallen, M. J., Nisan, I., Neves, B. C., Bain, C., Wolff, C., Dougan, G. \& Frankel, G. (1998). A novel EspAassociated surface organelle of enteropathogenic Escherichia coli involved in protein translocation into epithelial cells. EMBO J 17, 2166-2176.

Lai, L. C., Wainwright, L. A., Stone, K. D. \& Donnenberg, M. S. (1997). A third secreted protein that is encoded by the enteropathogenic Escherichia coli pathogenicity island is required for transduction of signals and for attaching and effacing activities in host cells. Infect Immun 65, 2211-2217.

Levine, M. M., Bergquist, E. J., Nalin, D. R., Waterman, D. H., Hornick, R. B., Young, C. R. \& Sotman, S. (1978). Escherichia coli strains that cause diarrhoea, but do not produce heat-labile or heat-stable enterotoxins and are non-invasive. Lancet 1, 1119-1122.

Li, Y., Frey, E., Mackenzie, A. M. R. \& Finlay, B. B. (2000). Human response to Escherichia coli $\mathrm{O} 157: \mathrm{H} 7$ infection: antibodies to secreted virulence factors. Infect Immun 68, 5090-5095.

McDaniel, T. K. \& Kaper, J. B. (1997). A cloned pathogenicity island from enteropathogenic Escherichia coli confers the attaching and effacing phenotype on E. coli K-12. Mol Microbiol 23, 399-407.

McNamara, B. P., Koutsouris, A., O'Connell, C. B., Nougayrede, J. P., Donnenberg, M. S. \& Hecht, G. (2001). Translocated EspF protein from enteropathogenic Escherichia coli disrupts host intestinal barrier function. J Clin Invest 107, 621-629.

Mellies, J. L., Elliott, S. J., Sperandio, V., Donnenberg, M. S. \& Kaper, J. B. (1999). The Per regulon of enteropathogenic Escherichia coli: identification of a regulatory cascade and a novel transcriptional activator, the locus of enterocyte effacement (LEE)-encoded regulator (Ler). Mol Microbiol 33, 296-306.

Rosenshine, I., Donnenberg, M. S., Kaper, J. B. \& Finlay, B. B. (1992). Signal transduction between enteropathogenic Escherichia coli (EPEC) and epithelial cells: EPEC induces tyrosine phosphorylation of host cell proteins to initiate cytoskeletal rearrangement and bacterial uptake. EMBO J 11, 3551-3560.

Rosenshine, I., Ruschkowski, S., Stein, M., Reinscheid, D. J., Mills, S. D. \& Finlay, B. B. (1996). A pathogenic bacterium triggers epithelial signals to form a functional bacterial receptor that mediates actin pseudopod formation. EMBO J 15, 2613-2624.

Shaw, R. K., Daniell, S., Ebel, F., Frankel, G. \& Knutton, S. (2001). EspA-filament-mediated protein translocation into red blood cells. Cell Microbiol 3, 213-222.

Wachter, C., Beinke, C., Mattes, M. \& Schmidt, M. A. (1999). Insertion of EspD into epithelial target cell membranes by infecting enteropathogenic Escherichia coli. Mol Microbiol 31, 1695-1707. 
Warawa, J. \& Kenny, B. (2001). Phosphoserine modification of the enteropathogenic Escherichia coli Tir molecule is required to trigger conformational changes in Tir and efficient pedestal elongation. Mol Microbiol 42, 1269-1280.

Warawa, J., Finlay, B. B. \& Kenny, B. (1999). Type III secretiondependent hemolytic activity of enteropathogenic Escherichia coli. Infect Immun 67, 5538-5540.
Wolff, C., Nisan, I., Hanski, E., Frankel, G. \& Rosenshine, I. (1998). Protein translocation into HeLa cells by infecting enteropathogenic Escherichia coli. Mol Microbiol 28, 143-155.

Received 16 October 2001; revised 21 December 2001; accepted 21 December 2001 